\title{
DC Countershock for Cardiac Arrhythmias
}

\author{
Toshio Mitsui, M.D.
}

Arrhythmias associated with various cardiac diseases, such as atrial fibrillation, atrial flutter, ventricular fibrillation and ventricular tachycardia, were terminated by DC countershock.

Methods and results of treatment, complications, hemodynamic changes and recurrence problems of cardioversion for atrial fibrillation were discussed.

This technique was turned out to be more effective, simple and secure for treatment of various arrhythmias. In order to maintain normal rhythm after cardioversion, antiarrhythmic pharmacological agents should be required.

$\mathrm{T}$

HE use of electrical discharge for cardiac resuscitation has a long history. In 1899, Prevost and Batelli') found that AC (alternating current) and DC (direct current) shocks directly or transthoracically applied to the heart of the dog or adult cat were one means to reverse the fibrillating heart to the normal one. In 1936, Ferris and his co-workers ${ }^{2)}$ reported their experiences with successful transthoracic $\mathrm{AC}$ shock in animals and described a significance of the vulnerable phase of the cardiac cycle in their studies. About the same year Wiggers ${ }^{3)}$ opened a new vista to standardized popularization of openchest AG shock which was a leading cardiac resuscitation method for many years. Afterwards, Beck ${ }^{4}$ and others applied AG shock to the patients for defibrillation. Especially in heart surgery this method was commonly accepted as an effective means to resuscitate the accidentally fibrillated heart. In 1961, Alexander ${ }^{5)}$ reported the successful reversion of ventricular tachycardia to sinus rhythm.

On the other hand, from an investigative point of view, DC shock has been studied. First in 1946, Gurvich and Yuniev6) reported their extensive experiments with transthoracic condenser discharge. They had shown that, by introduction of an inductive resistance, discharge time was lengthened and efficacy of the shock was improved as well. ${ }^{7)}$ Following that they strongly advocated the use of this mode of countershock in man. Important studies confirming and amplifying this earlier work were performed by Mackay and Leeds $^{81}$ in 1953. This knowledge, however, had not been practically pub-

\footnotetext{
From the Departments of Surgery and Thoracic Surgery, Faculty of Medicine, the University of Tokyo.

Received for publication November 20, 1965.
} 
licized until the last few years. In 1962, about one decade later, Lown ${ }^{9}$ brought this method into clinical application. Since he had applied the synchronized capacitor discharge ("Cardioversion") for termination of various kinds of arrhythmias, effectiveness, simplicity and security of this technique has made DC shock more excellent means in place of quinidine, procain amide and other antiarrhythmic agents.

By the author at the University of Tokyo Hospital, 42 patients of atrial fibrillation, 1 of atrial flutter, 64 of ventricular fibrillation and 1 of ventricular tachycardia were treated by this means (Table I).

Table I. The Results of Clinical Application of DC Shock

\begin{tabular}{l|l|c|c|c|c}
\hline Nature of Arrhythmias & $\begin{array}{c}\text { Mode of } \\
\text { Application }\end{array}$ & $\begin{array}{c}\text { Patients, } \\
\text { No. }\end{array}$ & $\begin{array}{c}\text { Shocks, } \\
\text { No. }\end{array}$ & $\begin{array}{c}\text { Success, } \\
\text { No. }\end{array}$ & $\begin{array}{c}\text { Percent } \\
\text { Success }\end{array}$ \\
\hline Atrial Fibrillation & $\left\{\begin{array}{l}\text { Direct* } \\
\text { Transthoracial }\end{array}\right.$ & 15 & 15 & 14 & 93 \\
Atrial Flutter & Transthoracial & 1 & 34 & 31 & 91 \\
Ventricular Fibrillation & Nirect* & 58 & 58 & 1 & 100 \\
Ventricular Tachycardia & Transthoracial & 6 & 32 & 29 & 93 \\
& Transthoracial & 1 & 3 & 3 & 100
\end{tabular}

* Performed in the open-chest operation.

The clinical application of DC countershock will be described in the following, mainly about that for atrial fibrillation and ventricular tachycardia including others.

\section{Methods}

The equipment for DC shock is a capacitor discharge type defibrillator of 180 watt-sec. of maximum power $(3,000 \mathrm{~V}$., $40 \mu \mathrm{F}$. with $1 \mathrm{H}$ choke coil).

In the reversion of arrhythmias other than ventricular fibrillation to sinus rhythm, this capacitor discharge can be synchronized to $\mathrm{R}$ spike not to fall in the vulnerable period of the cardiac cycle. The $\mathrm{R}$ spike synchronizer, however, has not been used in our 28 cases by the following reasons; defibrillation discharge can be switched on with care not to be applied at the ventricular vulnerable period which lasts only for 20 to $30 \mathrm{msec}$, a few percent long of one cardiac cycle and ventricular fibrillation rarely occurs by such current discharge as strong as 20 to 30 ampere even at the vulnerable period which may be explained by some myocardial physiological properties including "no response phenomenon ".18) But no necessity of $\mathbf{R}$ spike synchronization still remains in question which should be further studied.

For transthoracical application, 2 electrode paddles were placed over the right parasternal area at the third intercostal space and over the left mid-axillary line at the fifth intercostal space respectively.

The patients were placed in the supine position and anesthetized slightly with short-acting intravenous barbiturate or under endotracheal gas anesthesia in the operation room. 


\section{Results AND Discussion}

\section{Atrial Fibrillation}

Fifteen patients with atrial fibrillation were treated by cardioversion directly applied to the heart and 27 patients transthoracically with success rates of $93 \%$ and of $91 \%$ respectively.

Fundamental diseases. Diseases complicated with atrial fibrillation were listed in Table II. In our clinic of surgical department, cardioversion was done mostly on mitral stenosis patients with atrial fibrillation after mitral commissurotomy.

Table II. Diseases Complicated with Atrial Fibrillation

\begin{tabular}{l|r}
\hline M S & 31 \\
M S I & 4 \\
M I & 1 \\
Coronary Sclerosis & 1 \\
Congenital Heart Disease & 5
\end{tabular}

Energy of capacitor discharges. Energy of capacitor discharges is shown in Table III. In the early experiences of DC shock, most of cases were treated directly in the open chest surgery for emergency. In these days they were treated transthoracically by the following reason; the transient ST elevation on ECG after the discharge was scarcely observed in the transthoracical shock application in comparison with the direct one to the myocardium.

Table III. Energy of Capacitor Discharges

\begin{tabular}{c|c|c|c|c}
\hline \multirow{2}{*}{$\begin{array}{c}\text { Energy } \\
\text { (watt-sec.) }\end{array}$} & \multicolumn{2}{|c|}{ No. Successful } & \multicolumn{2}{|c}{ No. Failed } \\
\hline 125 & Direct & Transthoracic & Direct & Transthoracic \\
100 & & 4 & & 1 \\
80 & & 5 & 1 & 1 \\
50 & 10 & 9 & 1 \\
20 & 4 & 31 & 1 & 3 \\
\hline
\end{tabular}

The energy for conversion in successful cases was 20 to 50 watt-sec. in the direct discharge, while 50 to 125 watt-sec. in the transthoracical one. The energy employed was less than that reported by Lown ${ }^{9)}$ and others. ${ }^{10)}$

Arrhythmias related to cardioversion. Arrhythmias after cardioversion are 
Table IV. Arrhythmias after Cardioversion before Appearing Sinus Rhythm

\begin{tabular}{l|l}
\hline Atrioventricular Dissociation & 9 \\
Atrial Flutter & 2 \\
Atrioventricular Nodal Rhythm & 3 \\
Ventricular Tachycardia & 1
\end{tabular}

Table V. Nature of Arrhythmias Appeared after Reversion to Sinus Rhythm

\begin{tabular}{l|l}
\hline Extrasystoles & 9 \\
Atrial & 2 \\
Atrioventricular Nodal & 6 \\
Ventricular & 4
\end{tabular}

listed in Tables IV and $\mathrm{V}$. In most of cases distinct $\mathbf{P}$ wave appeared a few seconds later after the electrical discharge. But atrioventricular dissociation, atrial flutter, atrioventricular nodal rhythm and multifocal transient ventricular tachycardia were observed for several seconds to minutes in some cases prior to reversion to regular sinus rhythm. It is considered that sinus node activity did not return to normal just after the cardioversion in these cases as reported by Lemberg. ${ }^{10)}$ In a case of Uhl's disease, ${ }^{17)}$ hypoplasia of the right ventricular myocardium with right atrial hyperdilatation, the interesting ECG findings which showed various transient arrhythmias after the shock before conversion to sinus rhythm were observed as illustrated in Fig. 1.

ת (1600 V. $40 \mu$ F. 50 ws. Direct)

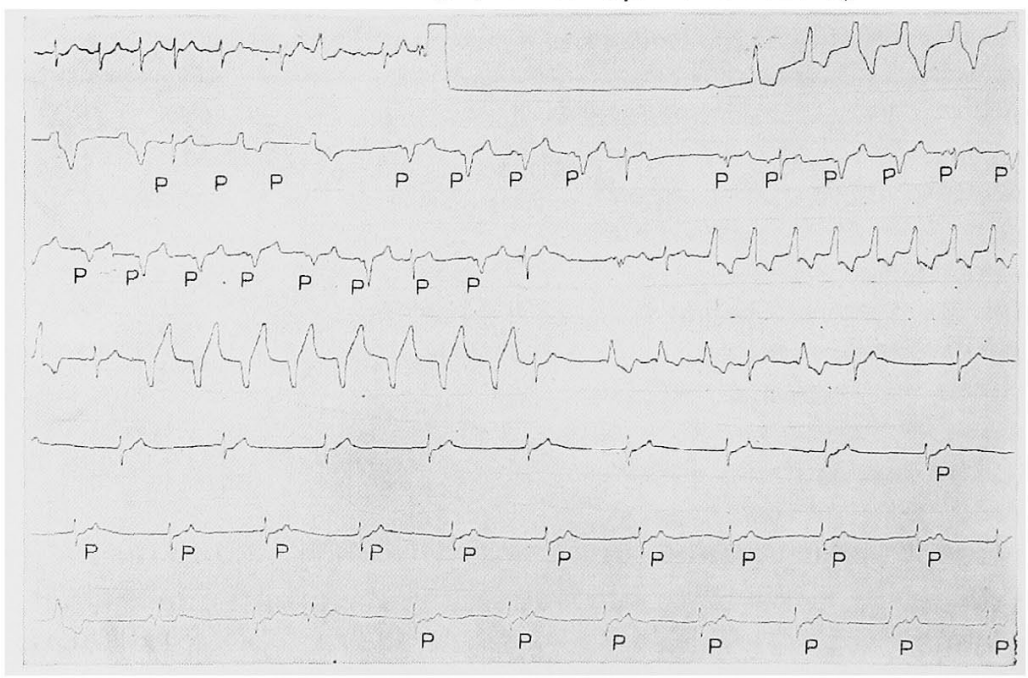

Fig. 1. The arrhythmias after cardioversion in a case of Uhl's disease. 
In a few cases after reversion to sinus rhythm, various extrasystoles or atrioventricular nodal rhythm extraordinally appeared for several hours to days. In those whose arrhythmias of these kinds had not disappeared for long time but appeared more frequently as time passed, atrial fibrillation recurred frequently. It is considered that some disorders on inhomogeneity in atrial excitability would be responsibile for the following recurrence of atrial fibrillation.

Hemodynamic changes related to cardioversion. Kahn and his co-workers ${ }^{11}$ reported the cardiac output study before and after cardioversion and found 22 to 25 per cent increase after cardioversion in 16 post mitral commissurotomy patients.

Cardiac output at rest was measured according to Fick's law before and after cardioversion of 5 patients 1 to 4 weeks after mitral commissurotomy. As the result, 6 to 25 (average 14.5) per cent increase in 4 cases and 12 per cent decrease in 1 case were observed as illustrated in Fig. 2.

Left atrial pressure before and immediately after cardioversion was measured during the operation of mitral commissurotomy. A distinct decrease of the left mean atrial pressure was observed after cardioversion (Fig. 3).

These findings suggest the improvement of cardiac hemodynamics and also a favorable influence upon prognosis of the postcommissurotomy patients by the restoration to sinus rhythm.

Complications of cardioversion. Temporary ST elevation on ECG was observed in 4 cases, especially in the cases of direct application of the electrode

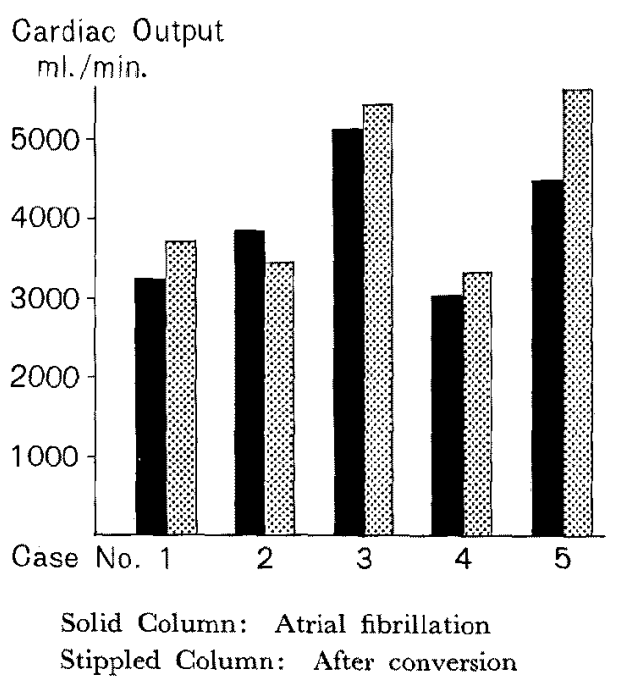

Fig. 2. Cardiac output before and after cardioversion. 
paddles. These changes, however, almost disappeared in a few minutes (Fig. 4). Slight erythema, the first grade of burn, and regional pain over the chest attached the electrodes were complained in 6 cases, but these side effects dis-

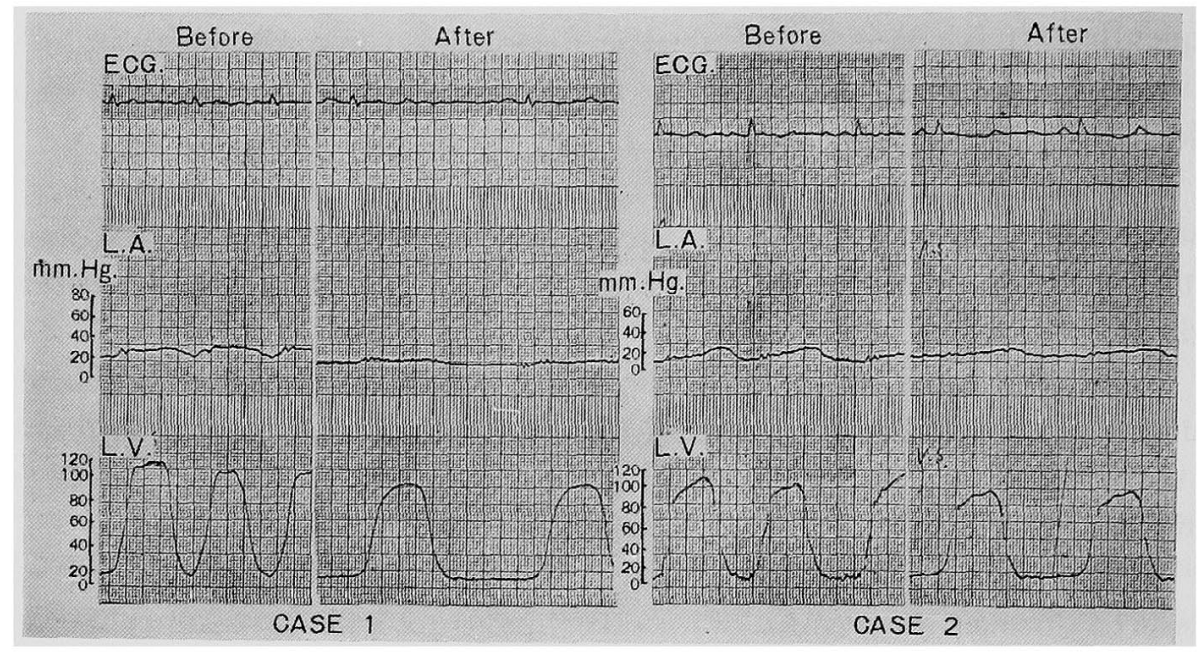

Fig. 3. Left atrial pressure before and after cardioversion.

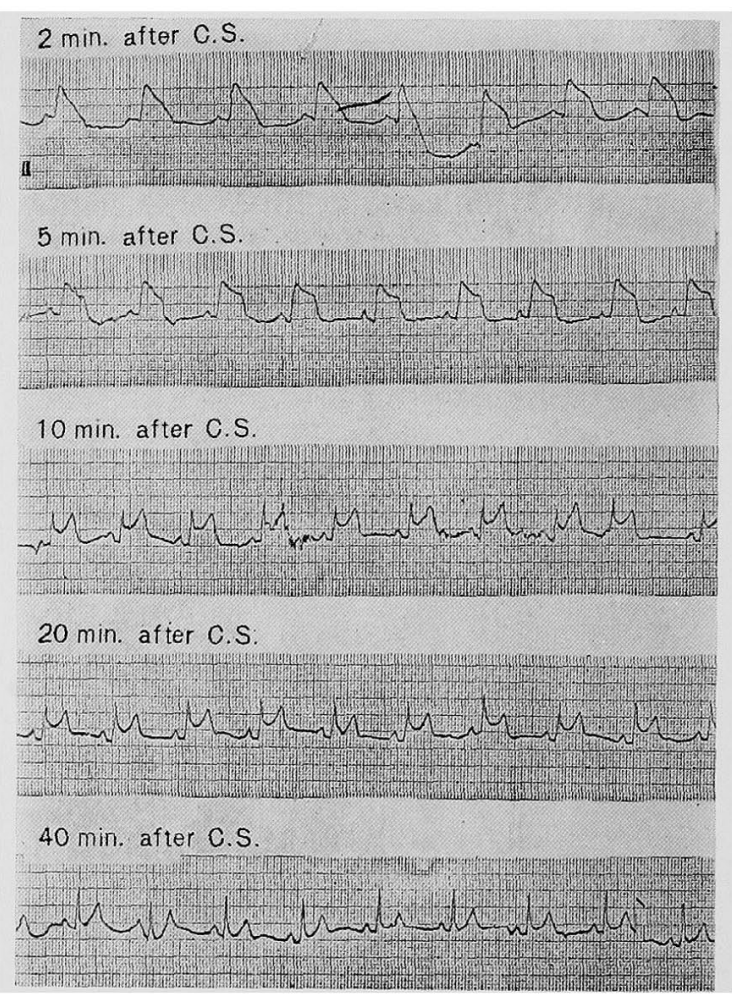

Fig. 4. ST elevation caused by countershock. 
appeared in a few days. Ventricular fibrillation, hypotension, dyspnea, embolism or other serious complications were not observed.

Recurrence of atrial fibrillation. To date, 28 cases subjected to cardioversion after the mitral valve operation were followed up with the recurrence rates of 43 per cent, 12 out of 28 cases.

Relationships between the recurrence of atrial fibrillation and the duration of atrial fibrillation prior to the conversion, the clinical grades by NYHA classification, the grades of commissurotomy by our classification*12) and the pre- and postoperative end-diastolic pressure gradient were investigated. The results are summarized in Fig. 5. The solid circle represents a recurrent

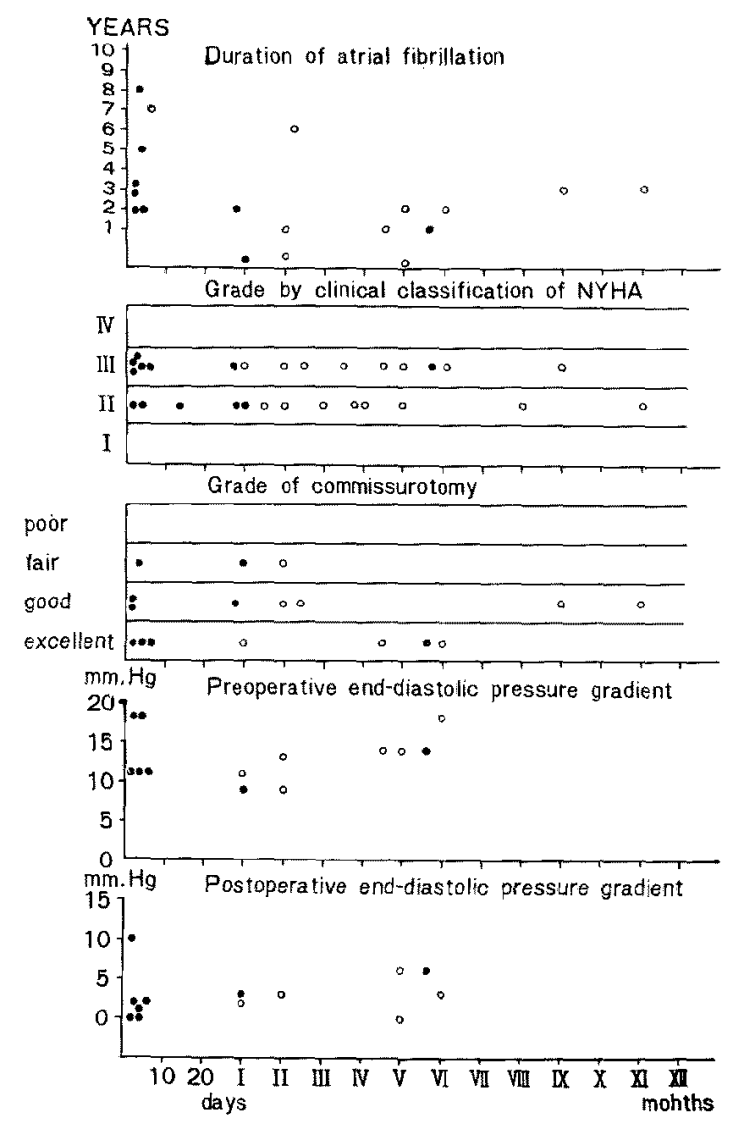

Fig. 5. The sustaining period of sinus rhythm vs, the clinical and laboratory data.

* Commissures are divided neither reaching T. I. (grade 1, poor); both reaching T. I., not past T.I. or reaching V.R. on one side, not reaching T.I. on the other side (grade 2, fair) ; both past T.I., not reaching V.R. or reaching V.R. on one side, reaching T.I. on the other side (grade 3, good) ; and both reaching V.R. (grade 4 , excellent).

T.I. = Critical areas of tendon insertion (Brock, 1952).

V.R. = Valvular ring. 
case while the open one indicates an individual case in which no recurrence was followed up at the time of study. There is no apparent correlation between these clinical and laboratory data and the recurrence of atrial fibrillation, but it was revealed that in most of occasions atrial fibrillation recurred within several days.

As the "defibrillation maintenance" agents, quinidine compounds ${ }^{13), 14}$ 10 to $15 \mathrm{mg}$. per $\mathrm{Kg}$. or T.T.F.D. * $* 300 \mathrm{mg}$. was administered daily from the day before cardioversion for around 2 weeks.

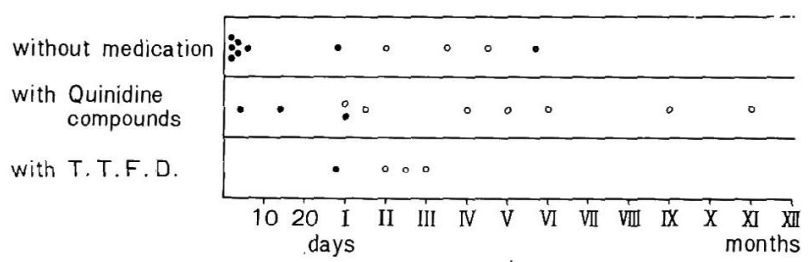

Fig. 6. Defibrillation maintenance agents and sustaining period of sinus rhythm.

Fig. 6 indicates the effect of these drugs to defibrillation maintenance showing a significant difference between the groups with and without medication and a questionable difference between these agents of which problem should be further determined.

\section{Ventricural Tachycardia}

Case report: A 21-year-old man experienced an abrupt attack of syncope in February, 1961. He was admitted to a hospital several times for the attacks with diagnosis of atrial flutter or fibrillation. On November 28, 1963, in the Department he was operated on the right pulmonary artery-superior vena cava anastomosis as Ebstein's disease. After one year's asymptomatic period, on January 14, 1965, he suddenly noticed acute palpitation, tachycardia and dyspnea. Before he was hospitalized again, eyelids edema, severe cough and increased body weight had been observed. On admission to the Hospital, ventricular tachycardia with regular heart rate of 160 per min., right bundle branch block on EGG, hypotension of 98/76 $\mathrm{mm} . \mathrm{Hg}$, dilatation of the heart configuration especially of the right heart on X-ray

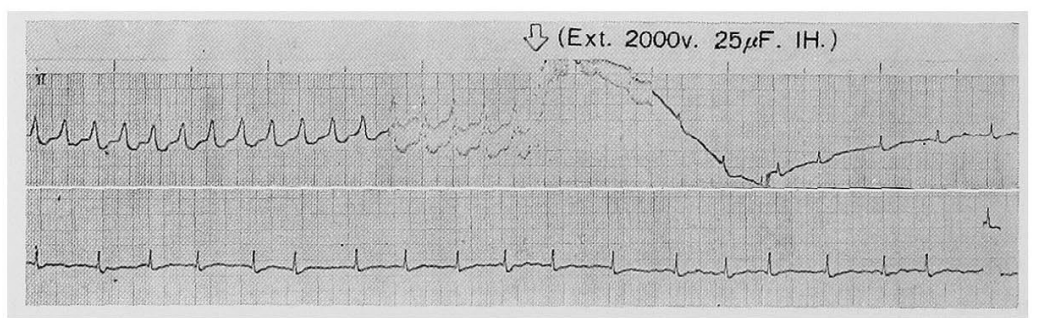

Fig. 7. The ECG of ventricular tachycardia reverted to atrial fibrillation.

\footnotetext{
** Thiamine tetrahydrofurfuryl disulfide, Alinamin of trade name of TAKedA Chemica Industries, Ltd.
} 
were noted. Propranolol, ${ }^{15},{ }^{16)}$ a $\beta$-receptor blocking agent, was not effective to the arrhythmia. On January 28, 1965, the patient was anesthetized slightly and a single 50 watt-sec. discharge was given resulting in immediate termination of ventricular tachycardia but not in that of atrial fibrillation (Fig. 7). After the cardioversion the patient felt comfortable, but ventricular tachycardia recurred in the midnight of that day with a cough. On February 3, 1965 the second cardioversion reverted the arrhythmia to atrial fibrillation. The patient was given $1 \mathrm{Gm}$. of procain amide daily after the reversion, but recurrence of the arrhythmia occurred with a yawn 2 days later. On February 17, 1965, the third trial of reversion was successfully performed. Bellergal, $* * *$ an autonomic inhibitor, and procain amide were administered as maintenance agents in consideration of contribution of the autonomic nerve influence upon this arrhythmia, which seemed to be helpful to prevent recurrence of ventricular tachycardia. Blood pressure was elevated, urine volume was increased, body weight was decreased and palpitation, dyspnea and anorexia disappeared. Two weeks later he was operated on under total body bypass. After right atriotomy it was found that the patient had Uhl's disease. ${ }^{17)}$ His clinical course is illustrated in Fig. 8.

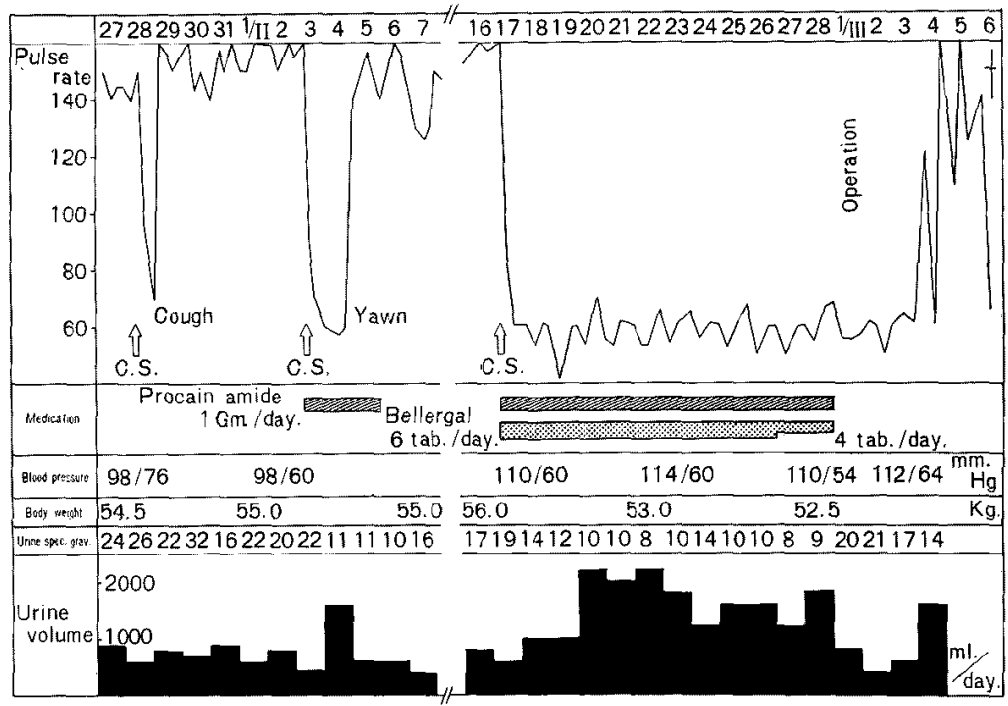

Fig. 8. The clinical record of a case of Uhl's disease.

In this case of Uhl's disease ventricular tachycardia with sudden onset was not responsive to antiarrhythmic drugs but was terminated by DC discharge and the recurrence of this arrhythmia could be avoided with administration of Bellergal and procain amide.

This case suggested contribution of the autonomic nerve to arrhythmia.

*** Trade name of the Pharmaceutical Dept. of SAndoz Ltd.

$\begin{array}{lr}\text { Bellafoline } & 0.1 \mathrm{mg} . \\ \text { Gynergen } & 0.3 \mathrm{mg} . \\ \text { Phenobarbital } & 20.0 \mathrm{mg} \text {. in a tablet. }\end{array}$




\section{SUMMARY}

The application of the capacitor discharge type defibrillator for treatment of various arrhythmias was reported.

Methods of treatment, complications, hemodynamic changes and recurrence problems of the cardioversion for atrial fibrillation were discussed.

Glinical experiences with a case of ventricular tachycardia complicated with Uhl's disease and its management were also reported.

\section{AGKnowledgement}

The author expresses his sincere gratitude to Professors S. Kimoto and S. Hatano for their guidance, to Associate Professor M. Saigusa and Dr. M. Hori for helpful advice, to Drs. K. Suma, T. Togawa, M. Tsunemoto, H. Sato, K. Nakamura, Z. Yamazaki, T. Go, R. Omoto, M. Hirose and Y. Fujimori for their help, and to Associate Professor T. Hoshi for his review.

\section{REFERENGES}

1. Prevost, J. L. and Batelli, F.: J. de Physiol. et de Path. gen. 1 : 427, 1899-1900.

2. Ferris, L. P., King, B. G., Spence, P. W., and Williams, H. B. : Elect. Engng. 55 : 498, 1936.

3. Wiggers, C. J.: Am. J. Physiol 116: 161, 1936.

4. Beck, C. S., Pritchard, W. H., and Feil, H. S.: J.A.M.A. 135 : 985, 1947.

5. Alexander, S., Kleiger, R., and Lown, B.: J.A.M.A. 177: 916, 1961.

6. Gurvich, N. L. and Yuniev, G. S. : Am. Rev. Soviet Med. 3 : 236, 1946.

7. Gurvich, N. L. and Yuniev, G. S.: Am. Rev. Soviet Med. 4 : 252, 1947.

8. Mackay, R. S. and Leeds, S. E. : J. Appl. Physiol. 6 : 67, 1953.

9. Lown, B., Amarasingham, R., and Neuman, J.: J.A.M.A. 182 : 548, 1962.

10. Lemberg, L., Castellanos, A., Swenson, J., and Gosselin, A.: Girculation 30: 163, 1964.

11. Kahn, D. R., Wilson, W. S., Weber, W., and Sloan, H. : J. Thor. Cardiovas. Surg. 48 : 898, 1964.

12. Tsunemoto, M., Asano, K., Hasegawa, T., Go, T., and Saigusa, M.: Lung and Heart 11 : $299,1964$.

13. Shaftel, N. and Halpern, A.: Am. J. Med. Sci. 236: 184, 1958.

14. Tricot, R. and Nogrette, P.: Am. J. Med. Sci. 243: 215, 1962.

15. Tsolakas, T. C. et al. : Lancet ii : 1064, 1964.

16. Slomon, G.: Brit. Med. J. i : $895,1965$.

17. Uhl, H. S. M. : Bull. Johns Hopkins Hosp. 197: 205, 1952.

18. Brooks, C. McC., Hoffman, B. F., Suckling, E. E., and Orias, O.: Excitability of the Heart, Grune and Stratton, N. Y. and London, 1955. 